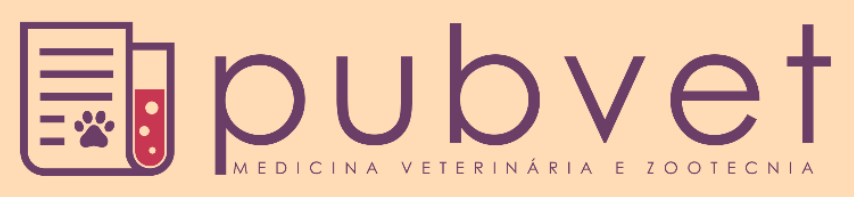

https://doi.org/10.31533/pubvet.v14n5a563.1-6

\title{
Perfil de susceptibilidade antimicrobiana de Staphylococcus spp. associados a mastite bovina
}

\author{
Larissa Sayuri Kurosawa $^{1} \oplus$, Lívia Mara Lambert Cézar ${ }^{1}{ }^{\oplus}$, Fábio Augusto Marques $^{1}{ }^{\ominus}$, Maria \\ Raquel de Godoy Oriani $^{2}{ }^{\circ}$, Maria Eugênia Moraes ${ }^{\circ}$
}

${ }^{I}$ Graduando(a) da Fundação de Ensino Superior de Bragança Paulista - FESB, Faculdade de Ciência e Letras, Bragança Paulista - SP Brasil. ${ }^{2}$ Bióloga, Professora Doutora da FESB, Departamento de Medicina Veterinária. Bragança Paulista-SP Brasil

${ }^{3}$ Médica Veterinária, Professora Mestre da FESB e da Universidade Guarulhos, Departamento de Medicina Veterinária. Bragança Paulista-SP Brasil. *Autor para correspondência,E-mail: eugeniavet@gmail.com

\begin{abstract}
Resumo. O presente estudo teve o principal objetivo de isolar e identificar Staphylococcus spp. coagulase positiva (SCP) e negativa ( $\mathrm{SCN}$ ), em vacas com suspeitas de mastite, e determinar o seu perfil de sensibilidade a antimicrobianos. Para isso, utilizou-se 29 amostras de Staphylococcus spp. coletadas em duas propriedades rurais da região Bragantina (SP) e identificadas através de testes como coloração de Gram, catalase, semeadura em ágar Manitol e a realização de coagulase. As amostras foram classificadas em Staphylococcus coagulase positiva $(34,48 \%)$ e Staphylococcus coagulase negativa $(65,52 \%)$. Foi realizado o antibiograma pela técnica de difusão em discos padronizada por Kirby-Bauer. A penicilina apresentou maior porcentagem de amostras resistentes $(34,48 \%)$, seguido por oxacilina $(20,69 \%)$ e eritromicina $(17,24 \%)$. Observou-se maior sensibilidade aos seguintes antimicrobianos: gentamicina $(96,55 \%)$ e a tetraciclina $(82,76 \%)$. O uso errôneo e desordenado pode proporcionar maior seleção de bactérias resistentes a antimicrobianos. Assim, a cultura microbiana e o antibiograma são técnicas que devem ser utilizadas para o diagnóstico da mastite favorecendo a escolha adequada do tratamento. Conclui-se que as medidas de manejo sanitário e a prevenção da mastite bovina devem ser valorizadas de forma que se reduza o uso de antimicrobianos na bovinocultura leiteira, o que pode ser alcançado através de ações educacionais e de extensão rural.
\end{abstract}

Palavras chave: antimicrobianos, leite, mastite, resistência, Staphylococcus spp

\section{Antimicrobial susceptibility profile of Staphylococcus spp. associated with bovine mastitis}

\footnotetext{
Abstract. The purpose of the present study was isolation and identification of the coagulase-positive Staphylococcus (CoPS) and the coagulase-negative Staphylococcus (CoNS) in cows suspected of having mastites and determine your antimicrobial susceptibility profile. For this 29 samples of Staphylococcus spp. were used. They were collected in two rural properties around the Bragantina (SP) zone and identified through tests such as Gram staining, catalase test, seeded agar plates, Manitol salt agar test and the coagulase test. The samples were classified as coagulase- positive Staphylococcus $(34,48 \%)$ and coagulase-negative Staphylococcus $(65,52 \%)$. The antibiogram was performed using the Kirby-Bauer disk diffusion technique. The highest percentage of resistant samples occurred with Penicillin $(34,48 \%)$, followed by Oxaciline $(20,69 \%)$ and Erythromycin $(17,24 \%)$. More sensibility to the following antimicrobials was observed: Gentamicin (96,55\%), Tetracycline (87,76\%). The misuse and overuse can cause a bigger amount of bacteria resistant to the antimicrobials. Therefore, the microbiological culture
} 
and the antibiogram are techniques that ought to be used to establish a correct diagnosis of mastitis, thus helping with the choice of the treatment. The hygiene-sanitary management and prevention to bovine mastitis need to be considered important to assist with the reduction of the use of antimicrobials on dairy cattle, which can be reached through educational programs and actions and also through agricultural extension.

Keywords: antimicrobials, milk, mastitis, resistance, Staphylococcus spp.

\section{Introdução}

A produção leiteira no Brasil vem crescendo constantemente. Os primeiros dados da produção de leite foram registrados pela Organização das Nações Unidas para a Alimentação e a Agricultura (FAO) em 1961, que produziu 5,2 milhões de toneladas (Vilela et al., 2017). Segundo dados do Instituto Brasileiro de Geografia e Estatística (IBGE), no ano de 2018, o Brasil alcançou o patamar de 24,43 bilhões de litros de leite cru adquirido pelos laticínios (IBGE, 2019).

A mastite representa um dos principais problemas enfrentado pela bovinocultura leiteira causando prejuízos econômicos (Costa et al., 2017). O quadro de mastite é caracterizado por um processo inflamatório da glândula mamária, tratando de uma doença complexa de caráter infeccioso, a qual envolve diversos patógenos, ambiente e fatores inerentes ao animal (Almeida et al., 2015). As perdas econômicas são causadas pela queda de produção e qualidade do leite, aumento dos custos com mão de obra, gastos com medicações e serviços veterinários, além do descarte precoce dos animais (Coser et al., 2012; Zanette et al., 2010).

A ocorrência de mastite envolve três fatores: o ambiente, a resistência do animal e o agente patogênico. Esses três fatores terão influência direta na ocorrência e na forma de manifestação da doença, podendo ser divididas em mastite contagiosa, que o microrganismo sobrevive dentro do hospedeiro, e na maioria das vezes manifesta infecções subclínica e mastite ambiental, que são descritos como invasores oportunistas, o qual não está adaptado para a sobrevivência no hospedeiro, desencadeando infecções clínicas (Zimermann \& Araújo, 2017).

A mastite clínica exibe alterações visíveis, como, por exemplo, pus e grumos no leite, edema, endurecimento e aumento da temperatura da glândula mamária (Zimermann \& Araújo, 2017). A manifestação geralmente é aguda e com curta duração da doença, sendo causada por agentes do próprio ambiente onde há acúmulo de esterco, barro, urina ou camas orgânicas. Entretanto, pode acometer todas as categorias, sendo, vacas em lactação, secas ou novilhas (Alencar et al., 2014).

O diagnóstico da mastite clínica é realizado pelo teste da caneca do fundo preto, no qual os primeiros jatos de cada teto são recolhidos e observados, podendo detectar possíveis grumos, alteração na coloração do leite, pus ou até mesmo sangue. O leite com alterações não poderá ser utilizado (Coser et al., 2012).

A mastite subclínica não apresenta alterações visíveis a olho nu, porém ocorre o aumento da contagem de células somáticas (CCS) no leite. A realização do Califórnia Mastitis Test (CMT), que consiste em um método químico indireto, poderá identificar o aumento de células somáticas. O CMT deverá ser realizado no rebanho, no momento da ordenha (Brito et al., 1997). A mastite subclínica têm como características uma maior duração, os agentes bacterianos têm como habitat a glândula mamária ou a pele dos tetos do bovino leiteiro e, portanto, são mais comuns em vacas lactantes (Alencar et al., 2014).

Para evitar a transmissão dos agentes causadores da mastite, usam-se meios de prevenção como, prédipping e pós-dipping, lavagem das mãos dos ordenhadores e tetos com água e sabão neutro antes da manipulação, higiene correta das teteiras e uso de papel toalha ou pano individual para cada animal (Zimermann \& Araújo, 2017). Muitos microrganismos estão relacionados à mastite bovina. As bactérias do gênero Staphylococcus, tem se destacado como causa de mastite, levando a perdas da qualidade do leite e econômicas. Os Staphylococcus spp. podem ser coagulase positiva (SCP) ou coagulase negativa (SCN), sendo os SCN consideradas oportunistas, ou seja, causam mastites clínica, e os SCP infecciosos causando mastite subclínica (Lopes et al., 2014; Noel et al., 2016). O Staphylococcus aureus é a principal espécie de SCP e é um patógeno frequentemente associado à mastite contagiosa bovina 
(Gasparotto et al., 2016), sendo este coagulase positiva (Salaberry et al., 2016). A principal causa para uso de antimicrobianos em gado leiteiro é para tratamentos e controle de mastite. Contudo, a utilização errônea e abusiva contribuiu para o desenvolvimento de resistência dos patógenos, dificultando o sucesso do tratamento das infecções (Zanette et al., 2010). De acordo com a Organização mundial da saúde animal (OIE) o uso excessivo ou inadequado de antimicrobianos pode levar ao surgimento de bactérias resistentes, que não respondem a tratamentos. Assim evitar a resistência bacteriana é de suma importância para a saúde humana e animal (OIE, 2018).

As cepas resistentes podem ser transmitidas aos seres humanos pela ingestão de produtos de origem animal contaminado. Além disso, animais em tratamentos, liberam resíduos de antibióticos no leite, que se consumido pode causar reações de hipersensibilidade em indivíduos mais sensíveis (Zanette et al., 2010). Já foram descritos no Brasil casos de infecções causadas por Staphylococcus aureus parcialmente resistentes aos antibióticos mais potentes e há relatos da capacidade de resistência dos SCN ser ainda maior em relação aos S. aureus (ANVISA, 2013; Salaberry et al., 2016). Desta forma, é de grande importância a identificação e isolamento desses agentes para a análise de sensibilidade antimicrobiana "in vitro". Para desenvolver métodos preventivos efetivos e estratégias para o tratamento e controle (Zanette et al., 2010).

Este trabalho teve como o objetivo isolar e identificar Staphylococcus spp. coagulase positiva e negativa ( $\mathrm{SCN}$ ) em vacas com suspeitas de mastite de duas propriedades da região bragantina do estado de São Paulo e determinar o perfil de sensibilidade a antimicrobianos, através de antibiograma.

\section{Material e métodos}

Foi realizada a coleta de leite em duas propriedades rurais, dos animais em lactação com indicativo de mastite pelo teste da caneca fundo preto e/ou CMT (De Vliegher et al., 2012). As amostras foram coletadas por quarto mamário suspeito, de forma que de um mesmo animal poderiam ser coletadas até quatro amostras. As amostras foram mantidas refrigeradas e no laboratório foram semeadas pela técnica de esgotamentos em ágar sangue. Após incubação de $48 \mathrm{~h}$ a $37^{\circ} \mathrm{C}$. Nas placas que havia crescimento bacteriano foi realizada a separação das colônias através da semeadura em ágar brain heart infusion broth (BHI), com a finalidade de obter uma cultura bacteriana "pura" e prosseguir com a identificação.

Para identificação dos Staphylococcus spp. realizou-se a coloração de Gram e apenas nas bactérias cocos Gram positivas foi realizado o teste da catalase e a semeadura em ágar Manitol, o qual é meio seletivo para Staphylococcus. Os Staphylococcus isolados foram então submetidos ao teste de coagulase para a classificação de Staphylococcus spp. coagulase positiva e negativa.

A partir da identificação dos SCP e SCN, foi realizada a avaliação do perfil de resistência "in vitro" através do método de difusão em placas de ágar Mueller Hinton conforme descrito por Bauer et al. (1966) utilizando-se os seguintes discos antimicrobianos: eritromicina $(15 \mu \mathrm{g})$, gentamicina $(10 \mu \mathrm{g})$, oxacilina $(1 \mu \mathrm{g})$, penicilina $(10 \mu \mathrm{g})$ e tetraciclina $(30 \mu \mathrm{g})$.

\section{Resultados e discussão}

Foram realizados os seguintes testes: "Teste da caneca de fundo preto" e "California Mastitis Test em 40 animais (160 tetos), dos quais $26(65,0 \%)$ dos animais tiveram suspeita de mastite clínica ou subclínica em um ou mais tetos. Uma vez que as amostras foram coletadas por teto o total de amostras foram 39. Dentre as 39 amostras, 29 (74,4\%) delas obtiveram crescimento de Staphylococcus spp., sendo que $10(34,48 \%)$ destes resultados pôde-se localizar SCP e $19(65,5 \%) \mathrm{SCN}$.

Ao comparar as amostras com crescimento de Staphylococcus spp. com a positividade nos teste (CMT e caneca do fundo preto) realizado na coleta observou-se que $2(6,9 \%)$ delas foram positivas apenas para o teste da caneca de fundo preto, $25(86,2 \%)$ apenas para o CMT e $2(6,9 \%)$ para ambos os testes. Portanto, vale ressaltar a importância de se criar uma rotina para a realização do teste da caneca do fundo preto e do CMT, possibilitando a detecção de animais com mastite clínica e subclínica. Verificou-se o perfil de sensibilidade para os antibióticos escolhidos: eritromicina, gentamicina, oxacilina, penicilina e tetraciclina, tendo a sua classificação em sensível, intermediário e resistente, de acordo com o tamanho do halo de inibição em milímetros. O halo mensurado foi 
analisado de acordo com a tabela padrão fornecida pelo próprio fabricante (DME, 2018). Estes resultados estão apresentados na Tabela 1 .

Tabela 1. Classificação em número absoluto e percentual dos resultados obtidos no antibiograma das 29 amostras de Staphylococcus spp. oriundos de leite.

\begin{tabular}{|c|c|c|c|c|c|c|}
\hline \multirow{2}{*}{ Antibióticos } & \multicolumn{2}{|c|}{ Sensível } & \multicolumn{2}{|c|}{ Intermediário } & \multicolumn{2}{|c|}{ Resistente } \\
\hline & Número & $\%$ & Número & $\%$ & Número & $\%$ \\
\hline Eritromicina & 19 & 65,52 & 5 & 17,24 & 5 & 17,24 \\
\hline Gentamicina & 28 & 96,55 & 0 & 00,00 & 1 & 3,24 \\
\hline Oxacilina & 23 & 79,31 & 0 & 00,00 & 6 & 20,69 \\
\hline Penicilina & 19 & 65,52 & - & - & 10 & 34,48 \\
\hline Tetraciclina & 24 & 82,76 & 1 & 3,45 & 4 & 13,79 \\
\hline
\end{tabular}

A penicilina teve uma maior porcentagem de amostras que apresentaram resistência bacteriana $(34,5 \%)$ entre os demais antibióticos testados, ainda assim a maioria das amostras testadas eram sensíveis e semelhantes ao trabalho de Zanette et al. (2010) que teve como dados finais 46,15\% de amostras resistentes à penicilina. Assim, esses resultados corroboram com a ideia de que o Staphylococcus spp. oriundos de amostra de leite com suspeita de mastite geralmente apresentam altos índices de resistências à penicilina (Zanette et al., 2010). Esta elevada porcentagem é descrita na maioria dos trabalhos referentes à susceptibilidade antimicrobiana com o grupo dos betalactâmicos. Em relação à penicilina, por exemplo, no estudo de Noel et al. (2016) encontrou-se 99,5\% de resistência; enquanto em Salaberry et al. (2016) foi encontrado 81,8\%, tal fato sendo explicado segundo Zimermann \& Araújo (2017) por esses microrganismos produzirem betalactamases, tendo a capacidade de cindir o anel betalactâmico do antimicrobiano, caracterizando-se como principal mecanismo de resistência, e também, unindo-se ao uso indiscriminado e inadequado de subdosagens na medicina veterinária, a qual possibilita a seleção de Staphylococcus spp. resistentes, como consequência da eliminação de sensíveis.

A gentamicina foi o antibiótico para o qual encontrou-se maior porcentagem de sensibilidade (96,5\%). Dados semelhantes foram observados também nos estudos de Andrade et al. (2000) apresentando 90,7\% e também nos de Nader Filho et al. (2007) com 98,6\% de sensibilidade.

Em relação à tetraciclina, a porcentagem de resistência foi de $13,8 \%$, resultados próximos aos encontrados por Zafalon et al. (2008) de 18,2\% e por Salaberry et al. (2016) de 14,5\%. No entanto, Noel et al. (2016) que obtiveram uma resistência de 56\% e Zanette et al. (2010) de 30,8\%. Segundo os autores Zimermann \& Araújo (2017) a resistência à tetraciclina ocorre pela produção de uma proteína chamada $T e t$, a qual é responsável pelo transporte do antibiótico para fora da célula bacteriana. O uso equivocado da duração e dosagem do tratamento implica na seleção de bactérias resistentes, proporcionando assim o seu aumento, no entanto em redução no seu tratamento.

Para a oxacilina, detectou-se um percentual de sensibilidade de 79,3\%. Resultado semelhante aos obtidos por Noel et al. (2016) de 73,9\%. Entretanto, Salaberry et al. (2016) observaram valores inferiores, que apresentaram sensibilidade de $35,5 \%$. Portanto, há uma grande variação nos porcentuais de sensibilidade, sendo que provavelmente a utilização empírica e indiscriminada do antimicrobiano tenha contribuído para o aparecimento de linhagens resistentes (Andrade et al., 2000).

Quanto a eritromicina, no presente estudo foi verificado $17,2 \%$ de resistência, dados muito próximos aos encontrados no estudo de Noel et al. (2016), com o porcentual encontrado de 17,9\%. Valores muito baixos de resistência foram encontrados na pesquisa de Zafalon et al. (2008) apresentando 0,7\% e percentual nulo demonstrado por Salaberry et al. (2016).

Ao analisar os resultados obtidos apenas para as amostras SCP $(n=10)$, observa-se que a gentamicina apresentou $100 \%$ de sensibilidade, enquanto a oxacilina e a penicilina apresentaram $30 \%$ de resistência conforme apresentado na Tabela 2. Já em relação aos resultados referentes aos $\mathrm{SCN}(\mathrm{n}=19)$, verificouse que a gentamicina apresentou maior sensibilidade $(94,7 \%)$ e a penicilina maior resistência $(36,8 \%)$ presente na Tabela 3. 
Tabela 2. Classificação em número absoluto e percentual dos resultados obtidos no antibiograma das 10 amostras de Staphylococcus coagulase positivo oriundos de leite

\begin{tabular}{|c|c|c|c|c|c|c|}
\hline \multirow{2}{*}{ Antibióticos } & \multicolumn{2}{|c|}{ Sensível } & \multicolumn{2}{|c|}{ Intermediário } & \multicolumn{2}{|c|}{ Resistente } \\
\hline & Número & $\%$ & Número & $\%$ & Número & $\%$ \\
\hline Eritromicina & 6 & 60 & 3 & 30 & 1 & 10 \\
\hline Gentamicina & 10 & 100 & 0 & 00 & 0 & 00 \\
\hline Oxacilina & 7 & 70 & 0 & 00 & 3 & 30 \\
\hline Penicilina & 7 & 70 & - & - & 3 & 30 \\
\hline Tetraciclina & 9 & 90 & 0 & 00 & 1 & 10 \\
\hline
\end{tabular}

Todavia, é conhecido que o custo dos exames laboratoriais tem inibido a realização do isolamento, identificação e dos testes de sensibilidade in vitro dos agentes etiológicos da mastite bovina. Desse modo, na maioria das vezes, a escolha do medicamento anti-mastítico tem se baseado apenas no quadro clínico da enfermidade. Diante destes fatos, prejuízos ainda maiores têm sido experimentados pelos produtores rurais em decorrência dos insucessos obtidos no tratamento da mastite bovina (Freitas et al., 2005).

Tabela 3. Classificação em número absoluto e percentual dos resultados obtidos no antibiograma das 10 amostras de SCN oriundos de leite.

\begin{tabular}{|c|c|c|c|c|c|c|}
\hline \multirow{2}{*}{ Antibióticos } & \multicolumn{2}{|c|}{ Sensível } & \multicolumn{2}{|c|}{ Intermediário } & \multicolumn{2}{|c|}{ Resistente } \\
\hline & Número & $\%$ & Número & $\%$ & Número & $\%$ \\
\hline Eritromicina & 13 & 68,42 & 2 & 10,53 & 4 & 21,05 \\
\hline Gentamicina & 18 & 94,74 & 0 & 00,00 & 1 & 5,26 \\
\hline Oxacilina & 16 & 84,21 & 0 & 00,00 & 3 & 15,79 \\
\hline Penicilina & 12 & 63,16 & - & - & 7 & 36,84 \\
\hline Tetraciclina & 15 & 78,94 & 1 & 5,26 & 3 & 15,79 \\
\hline
\end{tabular}

\section{Conclusão}

No presente estudo observou-se diferentes taxas de resistência aos antimicrobianos testados, sendo a penicilina o antimicrobiano para o qual os Staphylococcus spp. isolados apresentaram maior taxa de resistência. Podemos sugerir que o uso frequente deste princípio ativo possa estar favorecendo a resistência ao mesmo. Assim, a cultura microbiana e o antibiograma são técnicas que devem ser utilizadas para o diagnóstico da mastite favorecendo a escolha adequada do tratamento. Conclui-se que as medidas de manejo sanitário e a prevenção da mastite bovina devem ser valorizadas de forma que se reduza o uso de antimicrobianos na bovinocultura leiteira, o que pode ser alcançado por ações educacionais e de extensão rural.

\section{Referências bibliográficas}

Alencar, T. A., Mendonça, E. da C. L., Marques, V. F., Melo, D. A., Rojas, A. C. M., da Motta, C. C., Santiago, G. S., Dubenczuk, F. C., Medeiros, P. T. C., \& Coelho, S. de M. O. (2014). Aspectos das condições higiênico-sanitárias em unidades leiteiras em municípios do estado do Rio de Janeiro, Brasil e análise dos agentes bacterianos envolvidos na etiologia das mastites. Brazilian Journal of Veterinary Medicine, 36(2), 199-208.

Almeida, L. A. B., Brito, M. A. V. P., Brito, J. R. F., Pires, F. A., \& Benites, N. R. (2015). Tratamento de mastite clínica experimental por meio de ordenhas múltiplas em vacas leiteiras inoculadas com Staphylococcus aureus. Arquivo Instituto Biológico, 72(1), 1-6.

Andrade, M. A., Dias Filho, F. de C., Mesquita, A. J., \& Rocha, P. T. (2000). Sensibilidade in vitro de Staphylococcus aureus isolados de amostras de leite de vacas com mastite subclínica. 36(2), 199-208.

ANVISA. (2013). Manual de microbiologia clínica para o controle de infecção relacionada à assistência à saúde (D. e identificação de bactérias de importância médica (ed.); Vol. 9). Ministério da Saúde.

Bauer, A. W., Kirby, W. M. M., Sherris, J. C., \& Turck, M. (1966). Antibiotic susceptibility testing by a standardized single disk method. American Journal of Clinical Pathology, 45(4), 493.

Brito, J. R. F., Caldeira, G. A. V., Verneque, R. S., \& Brito, M. A. V. P. (1997). Sensibilidade e especificidade do" California Mastitis Test" como recurso diagnóstico da mastite subclínica em 
relação à contagem de células somáticas. Pesquisa Veterinária Brasileira, 17(2), 49-53.

Coser, S. M., Lopes, M. A., \& Costa, G. M. (2012). Mastite bovina: controle e prevenção. Boletim Técnico, 93, 1-30.

Costa, H. N., Molina, L. R., Lage, C. F. A., Malacco, V. M. R., Facury Filho, E. J., \& Carvalho, A. Ú. (2017). Estimativa das perdas de produção leiteira em vacas mestiças Holandês x Zebu com mastite subclínica baseada em duas metodologias de análise. Arquivo Brasileiro de Medicina Veterinária e Zootecnia, 69(3), 579-586.

DME - Diagnóstico Microbiológicos Especializados. (2018). Antibiograma: Interpretação das zonas de inibição e concentração inibitória mínima. Disponível em: <http://www.dme.ind.br/wpcontent/uploads/Bula-de-Bancada-edição-2018.pdf>. Acesso em: 20 dez. 2018.

De Vliegher, S., Fox, L. K., Piepers, S., McDougall, S., \& Barkema, H. W. (2012). Invited review: Mastitis in dairy heifers: Nature of the disease, potential impact, prevention, and control. Journal of Dairy Science, 95(3), 1025-1040.

Freitas, M. F. L., Pinheiro Júnior, J. W., Stamford, T. L. M., Rabelo, S. S. A., Silva, D. R., da Silveira Filho, V. M., Santos, F. G. B., Sena, M. J., \& Mota, R. A. (2005). Perfil de sensibilidade antimicrobiana in vitro de Staphylococcus coagulase positivos isolados de leite de vacas com mastite no agreste do estado de pernambuco. Arquivo Do Instituto Biológico de São Paulo, 72(2), 171-177.

Gasparotto, P. H., Weber, F. K., Barbosa, V. A. A., de Moraes, L. B., Bicalhos, B., \& Sobral, F. O. S. (2016). Principais gêneros bacterianos causadores de matite isolados no Laboratório de Microbiologia Veterinária do Hospital veterinário do Centro Universitário Luterano de JiParaná/RO. Revista Veterinária Em Foco, 14(1), 60-70.

IBGE - Instituto Brasileiro de Geografia e Estatística. (2018). Indicadores IBGE: Estatística da produção pecuária. Disponível em: <https://biblioteca.ibge.gov.br/index.php/bibliotecacatalogo?id=72380\&view=detalhes $>$. Acesso em: 12 ago. de 2019.

Lopes, L. O., Lacerda, M. S. de, \& Ronda, J. B. (2014). Controle e profilaxia de mastite causada por Staphylococcus sp. em vacas leiteiras: revisão de literatura. Revista Científica de Medicina Veterinária, 12(22), 1-15.

Nader Filho, A., Ferreira, L. M., Amaral, L. A., Rossi Junior, O. D., \& Oliveira, R. P. (2007). Sensibilidade antimicrobiana dos Staphylococcus aureus isolados no leite de vacas com mastite. Arquivos Do Instituto Biológico, São Paulo, 74(1), 1-4.

Noel, C. C., Motta, F. S., Francisco, N. L. S. G., Almeida, N. R., \& Soares, L. C. (2016). Perfil de suscetibilidade antimicrobiana e produção de "slime" de isolados de Staphylococcus spp. provenientes de casos de mastite bovina na região sul-fluminense. Revista de Saúde, 7(1), 22-26.

OIE - World Organisation For Animal Health. (2018). Antimicrobial Resistance (AMR). Disponível em: <http://www.oie.int/en/for-the-media/amr/>. Acesso em: 10 mai. 2018.

Salaberry, S. R. S., Saidenberg, A. B. S., Zuniga, E., Gonsales, F. F., Melville, P. A., \& Benites, N. R. (2016). Análise microbiológica e perfil de sensibilidade do Staphylococcus spp. em mastite subclínica de caprinos leiteiros. Arquivo Brasileiro de Medicina Veterinária e Zootecnia, 68(2), 336-344.

Vilela, D., Resende, J. C., Leite, J. B., \& Alves, E. (2017). A evolução do leite no Brasil em cinco décadas. Revista de Política Agrícola, 26(1), 5-24.

Zafalon, L. F., Arcaro, J. R. P., Nader Filho, A., Ferreira, L. M., Castelani, L., \& Benvenutto, F. (2008). Investigação de perfis de resistência aos antimicrobianos em Staphylococcus aureus isolados na ordenha de vacas em lactação. Revista Do Instituto Adolfo Lutz, 67(2), 118-125.

Zanette, E., Scapin, D., \& Rossi, E. M. (2010). Suscetibilidade antimicrobiana de Staphylococcus aureus isolados de amostras de leite de bovinos com suspeita de mastite. Unoesc \& Ciência-ACBS, 1(1), $65-70$.

Zimermann, K. F., \& Araújo, M. E. M. (2017). Mastite bovina: agentes etiológicos e susceptibilidade a antimicrobianos. Campo Digital, 12(1), 1-7.

Recebido: 9 de janeiro, 2020.

Aprovado: 2 de março, 2020.

Disponível online: 4 maio, 2020.
Licenciamento: Este artigo é publicado na modalidade Acesso Aberto sob a licença Creative Commons Atribuição 4.0 (CC-BY 4.0), a qual permite uso irrestrito, distribuição, reprodução em qualquer meio, desde que o autor e a fonte sejam devidamente creditados. 